NBER WORKING PAPER SERIES

\title{
IS OPTIMAL CAPITAL-CONTROL POLICY COUNTERCYCLICAL IN OPEN-ECONOMY MODELS WITH COLLATERAL CONSTRAINTS?
}

\author{
Stephanie Schmitt-Grohé \\ Martín Uribe \\ Working Paper 22481 \\ http://www.nber.org/papers/w22481 \\ NATIONAL BUREAU OF ECONOMIC RESEARCH \\ 1050 Massachusetts Avenue \\ Cambridge, MA 02138 \\ August 2016, Revised June 2017
}

An earlier version of this paper circulated under the title "Revisiting Macroprudential Policy In Open-Economy Models With Financial Frictions." We thank for comments and suggestions two anonymous referees, Pierre-Olivier Gourinchas, Pau Rabanal, Damiano Sandri, and participants at the Swiss National Bank/IMF conference on "Exchange Rates and External Adjustment," held June 24-25, 2016 in Zurich. Yoon Joo Jo provided excellent research assistance. The views expressed herein are those of the authors and do not necessarily reflect the views of the National Bureau of Economic Research.

NBER working papers are circulated for discussion and comment purposes. They have not been peer-reviewed or been subject to the review by the NBER Board of Directors that accompanies official NBER publications.

(C) 2016 by Stephanie Schmitt-Grohé and Martín Uribe. All rights reserved. Short sections of text, not to exceed two paragraphs, may be quoted without explicit permission provided that full credit, including $\odot$ notice, is given to the source. 
Is Optimal Capital-Control Policy Countercyclical In Open-Economy Models With Collateral Constraints?

Stephanie Schmitt-Grohé and Martín Uribe

NBER Working Paper No. 22481

August 2016, Revised June 2017

JEL No. E44,F41

\section{ABSTRACT}

This paper contributes to a literature that studies optimal capital control policy in open economy models with pecuniary externalities due to flow collateral constraints. It shows that the optimal policy calls for capital controls to be lowered during booms and to be increased during recessions. These findings are at odds with the conventional view that capital controls should be tightened during expansions to curb capital inflows and relaxed during contractions to discourage capital flight.

Stephanie Schmitt-Grohé

Department of Economics

Columbia University

420 West 118th Street, MC 3308

New York, NY 10027

and NBER

stephanie.schmittgrohe@columbia.edu

Martín Uribe

Department of Economics

Columbia University

International Affairs Building

New York, NY 10027

and NBER

martin.uribe@columbia.edu 


\section{Introduction}

This paper contributes to a literature that studies optimal capital control policy in open economy models with pecuniary externalities due to flow collateral constraints. A central question in this literature is whether this type of model can rationalize macroprudential policy. The concept of prudential capital control policy has two main dimensions. One dimension concerns the long-run behavior of capital controls and asserts that capital controls should be positive on average to reduce overborrowing. The second dimension holds that capital control policy should be used countercyclically. Capital controls should be increased during booms and lowered during recessions. The existing literature has established that in open economy models with collateral constraints capital controls are indeed positive on average. Thus, this class of models is in line with the first dimension of macroprudential capital-control policy. The goal of this paper is to investigate whether in this class of models optimal capital-control policy is also consistent with the aforementioned second dimension of macroprudentiality.

To this end, we characterize Ramsey-optimal capital-control policy in an open economy with a flow collateral constraint. We focus on the case in which tradable and nontradable output have collateral value, because it is the type of flow collateral constraint most frequently studied in the related literature. This model features a pecuniary externality originating from the fact that the relative price of nontradable goods, which determines the value of collateral, is taken as given by households but does depend in equilibrium on their collective consumption and borrowing decisions.

The existing narrative of how this externality may call for countercyclical capital control policy is as follows. A positive shock that expands aggregate demand pushes the price of nontradables up raising the value of collateral and easing access to credit, which in turn amplifies the expansion in aggregate demand. Similarly, a negative shock that reduces aggregate demand leads to a decline in the relative price of nontradables making the value of nontradable output in terms of tradable goods fall and the collateral constraint tighten, which deepens the contraction. It is then natural to expect that a benevolent planner who internalizes the effect of domestic absorption on the value of collateral would have an incentive to tighten capital controls during booms and to ease them during busts, as a way to reduce the excess amplitude of the business cycle caused by the pecuniary externality.

We find that this intuition does not play out in the context of the models analyzed in this literature. The Ramsey-optimal policy calls for capital control taxes to be lowered during booms and to be increased during recessions. The correct intuition has to do with the way in which the Ramsey planner handles a characteristic of households that is ubiquitously 
assumed in quantitative models of collateral constraints, namely, that households are impatient in the sense that they discount the future at a higher rate than the market (in the usual terminology, $\beta(1+r)<1)$. This assumption is needed in all existing models to generate empirically plausible frequencies of financial crises. The Ramsey planner faces a trade-off. On the one hand, he wants to accommodate the household's desire to front load consumption via the accumulation of external debt. On the other hand, he wishes to avoid financial crises, because they are costly in terms of welfare as they require large cuts in consumption when the economy deleverages. The Ramsey planner resolves this trade-off by increasing debt taxes during contractions, because these are times when a financial crisis is most likely, and lowering them during booms, when a financial crisis is less likely.

Our baseline environment is identical to Bianchi (2011) along all dimensions, model, functional forms, driving forces, and calibration. This is an interesting point of reference, because it is a framework widely used in the related quantitative literature. The Bianchi model is driven by shocks to the endowments of tradable and nontradable goods. The central result of our investigation is that in the context of this model optimal capital controls are lowered during booms and raised during contractions.

We then extend the model to allow for interest rate shocks in addition to endowment shocks. This environment is of interest because interest rate shocks have been shown to be a major driver of business cycles in emerging countries (Neumeyer and Perri, 2005; Uribe and Yue, 2006; and García Cicco, Pancrazi, and Uribe, 2010) and yet are less common in quantitative models with collateral constraints. The central result of the paper is robust to this extension. The Ramsey planner finds it optimal to lower debt taxes during booms and to increase them during contractions.

This paper is related to a growing literature studying macroprudential policy in the context of open economy models with collateral constraints. Output-based flow collateral constraints were introduced in open economy models by Mendoza (2002). The externality that emerges when debt is denominated in tradable goods but leveraged on nontradable income and the consequent room for macroprudential policy is emphasized in Korinek (2011). Bianchi (2011) shows that the pecuniary externality leads to overborrowing and that the optimal capital control tax is positive on average, but does not characterize the cyclical properties of optimal capital controls, which is the focus of the present study. Benigno et al. (2013) introduce production and Benigno et al. (2014) introduce a tax on nontradables that makes the first best attainable. Uribe $(2006,2007)$ establishes that overborrowing does not depend on whether foreign lenders impose collateral constraints at the aggregate level or at the level of the individual agent. Bianchi, Liu, and Mendoza (2016) introduce noisy news and regime shifts in the world interest rate in an output-based flow collateral constraint economy 
and show that optimal debt taxes are decreasing in the precision of news. Bianchi and Mendoza (forthcoming) and Jeanne and Korinek (2010) show that in open economies with stock collateral constraints the optimal capital control policy is time inconsistent. Bianchi and Mendoza characterize time consistent debt tax policy and show that capital controls are positive when there is a positive probability that the collateral constraint will bind in the next period.

The remainder of the paper is presented in five sections. Section 2 presents the model. Section 3 characterizes the Ramsey-optimal capital control problem. Section 4 shows that optimal capital-control policy is procyclical in the Bianchi (2011) model, which as mentioned above is driven by tradable and nontradable endowment shocks. Section 5 establishes that the procyclical nature of optimal capital control policy is robust to allowing for countryinterest-rate shocks. Section 6 discusses the central results of the paper and concludes.

\section{The Model}

We perform the analysis in the context of a prototypical theoretical environment, namely, the one presented in Bianchi (2011). ${ }^{1}$ Consider a small open endowment economy in which households have preferences of the form

$$
\mathbb{E}_{0} \sum_{t=0}^{\infty} \beta^{t} U\left(c_{t}\right)
$$

where $c_{t}$ denotes consumption in period $t, U(\cdot)$ denotes an increasing and concave period utility function, $\beta \in(0,1)$ denotes a subjective discount factor, and $\mathbb{E}_{t}$ denotes the expectations operator conditional on information available in period $t$. The period utility function takes the CRRA form

$$
U(c)=\frac{c^{1-\sigma}-1}{1-\sigma}
$$

with $\sigma>0$. We assume that consumption is a composite of tradable and nontradable goods aggregated in a CES fashion,

$$
c_{t}=A\left(c_{t}^{T}, c_{t}^{N}\right) \equiv\left[a c_{t}^{T^{1-1 / \xi}}+(1-a) c_{t}^{N^{1-1 / \xi}}\right]^{1 /(1-1 / \xi)}
$$

where $c_{t}^{T}$ denotes consumption of tradables in period $t$ and $c_{t}^{N}$ denotes consumption of nontradables in period $t$. Households are assumed to have access to a single, one-period, risk-free, internationally-traded bond denominated in terms of tradable goods that pays the

\footnotetext{
${ }^{1}$ For a textbook presentation, see Uribe and Schmitt-Grohé (2017, chapter 12).
} 
interest rate $r_{t}$ when held from period $t$ to period $t+1$. The household's sequential budget constraint is given by

$$
c_{t}^{T}+p_{t} c_{t}^{N}+d_{t}=y_{t}^{T}+p_{t} y_{t}^{N}+\frac{d_{t+1}}{1+r_{t}},
$$

where $d_{t}$ denotes the amount of debt due in period $t$ and $d_{t+1}$ denotes the amount of debt assumed in period $t$ and maturing in $t+1$. The variable $p_{t}$ denotes the relative price of nontradables in terms of tradables, and $y_{t}^{T}$ and $y_{t}^{N}$ denote the endowments of tradables and nontradables, respectively. Both endowments are assumed to be exogenously given. The collateral constraint takes the form

$$
d_{t+1} \leq \kappa\left(y_{t}^{T}+p_{t} y_{t}^{N}\right)
$$

where $\kappa>0$ is a parameter. Households internalize this borrowing limit. Yet, the borrowing constraint introduces an externality, because each individual household takes the real exchange rate, $p_{t}$, as exogenously determined, even though in equilibrium their collective absorption is a key determinant of this relative price.

Households choose a set of processes $\left\{c_{t}^{T}, c_{t}^{N}, c_{t}, d_{t+1}\right\}$ to maximize (1) subject to (2)-(4), given the processes $\left\{r_{t}, p_{t}, y_{t}^{T}, y_{t}^{N}\right\}$ and the initial debt position $d_{0}$. The first-order conditions of this problem are (2)-(4) and

$$
\begin{gathered}
U^{\prime}\left(A\left(c_{t}^{T}, c_{t}^{N}\right)\right) A_{1}\left(c_{t}^{T}, c_{t}^{N}\right)=\lambda_{t}, \\
p_{t}=\frac{1-a}{a}\left(\frac{c_{t}^{T}}{c_{t}^{N}}\right)^{1 / \xi}, \\
\left(\frac{1}{1+r_{t}}-\mu_{t}\right) \lambda_{t}=\beta \mathbb{E}_{t} \lambda_{t+1}, \\
\mu_{t} \geq 0
\end{gathered}
$$

and

$$
\left(d_{t+1}-\kappa y_{t}^{T}-\kappa p_{t} y_{t}^{N}\right) \mu_{t}=0
$$

where $\beta^{t} \lambda_{t}$ and $\beta^{t} \lambda_{t} \mu_{t}$ denote the Lagrange multipliers on the sequential budget constraint (3) and the collateral constraint (4), respectively. The Euler equation (7) equates the marginal benefit of assuming more debt with its marginal cost. In periods in which the collateral constraint does not bind, one unit of debt payable in $t+1$ increases tradable consumption by $1 /\left(1+r_{t}\right)$ units in period $t$, which increases utility by $\lambda_{t} /\left(1+r_{t}\right)$. The marginal cost of an extra unit of debt assumed in period $t$ and payable in $t+1$ is the marginal utility of consumption in period $t+1$ discounted at the subjective discount factor, $\beta \mathbb{E}_{t} \lambda_{t+1}$. During 
financial crises, by which we mean periods in which the collateral constraint binds, the marginal utility of increasing debt falls to $\left[1 /\left(1+r_{t}\right)-\mu_{t}\right] \lambda_{t}$, reflecting a shadow penalty for trying to increase debt when the collateral constraint is binding.

In equilibrium, the market for nontradables must clear. That is,

$$
c_{t}^{N}=y_{t}^{N}
$$

Then, a competitive equilibrium is a set of processes $\left\{c_{t}^{T}, d_{t+1}, \mu_{t}\right\}$ satisfying

$$
\begin{gathered}
\left(\frac{1}{1+r_{t}}-\mu_{t}\right) U^{\prime}\left(A\left(c_{t}^{T}, y_{t}^{N}\right)\right) A_{1}\left(c_{t}^{T}, y_{t}^{N}\right)=\beta \mathbb{E}_{t} U^{\prime}\left(A\left(c_{t+1}^{T}, y_{t+1}^{N}\right)\right) A_{1}\left(c_{t+1}^{T}, y_{t+1}^{N}\right) \\
c_{t}^{T}+d_{t}=y_{t}^{T}+\frac{d_{t+1}}{1+r_{t}} \\
d_{t+1} \leq \kappa y_{t}^{T}+\kappa\left(\frac{1-a}{a}\right) c_{t}^{T^{1 / \xi}} y_{t}^{N^{1-1 / \xi}} \\
\mu_{t}\left[\kappa y_{t}^{T}+\kappa\left(\frac{1-a}{a}\right) c_{t}^{T^{1 / \xi}} y_{t}^{N^{1-1 / \xi}}-d_{t+1}\right]=0 \\
\mu_{t} \geq 0
\end{gathered}
$$

given processes $\left\{r_{t}, y_{t}^{T}, y_{t}^{N}\right\}$ and the initial condition $d_{0}$.

The fact that $c_{t}^{T}$ appears on the right-hand side of the equilibrium version of the collateral constraint (12) means that during contractions in which the aggregate absorption of tradables falls, the collateral constraint endogenously tightens. Individual agents fail to internalize that such movements in aggregate absorption are in part caused by their own expenditure choices. This is the nature of the pecuniary externality in this model.

From the perspective of the individual household, equations (3) and (4) define a convex set of feasible debt choices, $d_{t+1}$. That is, if two debt levels $d^{1}$ and $d^{2}$ satisfy (3) and (4), then any weighted average $\alpha d^{1}+(1-\alpha) d^{2}$ for $\alpha \in[0,1]$ also satisfies these two conditions. From an equilibrium perspective, however, this ceases to be true in general. The reason is that the relative price of nontradables, $p_{t}$, which appears on the right-hand side of the collateral constraint (4) is increasing in consumption of tradables by equation (6), which, in turn, is increasing in $d_{t+1}$ by the resource constraint (11). To see this, use equilibrium condition (11) to eliminate $c_{t}^{T}$ from equilibrium condition (12) to obtain

$$
d_{t+1} \leq \kappa y_{t}^{T}+\kappa\left(\frac{1-a}{a}\right)\left(y_{t}^{T}+\frac{d_{t+1}}{1+r_{t}}-d_{t}\right)^{1 / \xi} y_{t}^{N^{1-1 / \xi}}
$$

It is clear from this expression that the right-hand side is increasing in the equilibrium level 
of external debt, $d_{t+1}$. Moreover, depending on the values assumed by the parameters $\kappa, a$, and $\xi$, the equilibrium value of collateral may increase more than one for one with $d_{t+1}$. In other words, an increase in debt, instead of tightening the collateral constraint may relax it. In this case, the more indebted the economy becomes, the less leveraged it is. Schmitt-Grohé and Uribe (2016a) show that this feature of the model can give rise to self-fulfilling financial crises in which the price of collateral falls due to nonfundamental pessimistic sentiments. In the present paper, however, we limit attention to parameterizations for which the equilibrium is unique.

\section{Optimal Capital Control Policy}

The pecuniary externality created by the presence of the relative price of nontradables in the collateral constraint induces an allocation that is in general suboptimal, not only when compared to the allocation that would result in the absence of a collateral constraint, but also relative to the best allocation possible among all of the ones that satisfy the collateral constraint. As a result, the collateral constraint opens the door to welfare improving policy intervention. Here, like in much of the related literature (see Korinek, 2011; Bianchi, 2011) we study capital controls, because they essentially represent a tax on external borrowing, which is the variable most directly affected by the pecuniary externality. In fact, the optimal capital control policy fully internalizes the pecuniary externality, in the sense that it induces the representative household to behave as if it understood that its own borrowing choices influence the relative price of nontradables and therefore the value of collateral.

We assume that the government is benevolent in the sense that it seeks to maximize the well-being of the representative household. Further, we assume that the government has the ability to commit to policy promises. That is, we characterize the Ramsey optimal capital control policy in the context of an open economy with a flow collateral constraint.

Let $\tau_{t}$ be a proportional tax on debt acquired in period $t$. If $\tau_{t}$ is positive, it represents a proper capital control tax, whereas if it is negative it has the interpretation of a borrowing subsidy. The revenue from capital control taxes is given by $\tau_{t} d_{t+1} /\left(1+r_{t}\right)$. We assume that the government consumes no goods and that it rebates all revenues from capital controls to the public in the form of lump-sum transfers (lump-sum taxes if $\tau_{t}<0$ ), denoted $\ell_{t}$. The budget constraint of the government is then given by

$$
\tau_{t} \frac{d_{t+1}}{1+r_{t}}=\ell_{t} .
$$


The household's sequential budget constraint now becomes

$$
c_{t}^{T}+p_{t} c_{t}^{N}+d_{t}=y_{t}^{T}+p_{t} y_{t}^{N}+\left(1-\tau_{t}\right) \frac{d_{t+1}}{1+r_{t}}+\ell_{t}
$$

This expression makes it clear that the capital control tax distorts the borrowing decision of the household. In particular, the gross interest rate on foreign borrowing perceived by the private household is no longer $1+r_{t}$, but $\left(1+r_{t}\right) /\left(1-\tau_{t}\right)$. All other things equal, the higher is $\tau_{t}$, the higher is the interest rate perceived by households. Thus, by changing $\tau_{t}$ the government can encourage or discourage borrowing. All optimality conditions associated with the household's optimization problem (equations (5)-(9)) are unchanged, except for the debt Euler equation (7), which now takes the form

$$
\left(\frac{1-\tau_{t}}{1+r_{t}}-\mu_{t}\right) \lambda_{t}=\beta \mathbb{E}_{t} \lambda_{t+1}
$$

A competitive equilibrium in the economy with capital control taxes is then a set of processes $c_{t}^{T}, d_{t+1}, \lambda_{t}, \mu_{t}$, and $p_{t}$ satisfying

$$
\begin{gathered}
c_{t}^{T}+d_{t}=y_{t}^{T}+\frac{d_{t+1}}{1+r_{t}}, \\
d_{t+1} \leq \kappa\left[y_{t}^{T}+p_{t} y_{t}^{N}\right], \\
\lambda_{t}=U^{\prime}\left(A\left(c_{t}^{T}, y_{t}^{N}\right)\right) A_{1}\left(c_{t}^{T}, y_{t}^{N}\right), \\
\left(\frac{1-\tau_{t}}{1+r_{t}}-\mu_{t}\right) \lambda_{t}=\beta \mathbb{E}_{t} \lambda_{t+1}, \\
p_{t}=\frac{A_{2}\left(c_{t}^{T}, y_{t}^{N}\right)}{A_{1}\left(c_{t}^{T}, y_{t}^{N}\right)}, \\
\mu_{t}\left[\kappa\left(y_{t}^{T}+p_{t} y_{t}^{N}\right)-d_{t+1}\right]=0, \\
\mu_{t} \geq 0,
\end{gathered}
$$

given a policy process $\tau_{t}$, exogenous driving forces $y_{t}^{T}, y_{t}^{N}$, and $r_{t}$, and the initial condition $d_{0}$.

The benevolent government sets capital control taxes to maximize the household's lifetime utility subject to the restriction that the optimal allocation be supportable as a competitive equilibrium. Formally, the Ramsey-optimal competitive equilibrium are processes $\tau_{t}, c_{t}^{T}$, 
$d_{t+1}, \lambda_{t}, \mu_{t}$, and $p_{t}$ that solve the problem of maximizing

$$
\mathbb{E}_{0} \sum_{t=0}^{\infty} \beta^{t} U\left(A\left(c_{t}^{T}, y_{t}^{N}\right)\right)
$$

subject to (17)-(23), given processes $y_{t}^{T}, y_{t}^{N}$ and $r_{t}$ and the initial condition $d_{0}$. In the welfare function (24), we have replaced consumption of nontradables, $c_{t}^{N}$, with the endowment of nontradables, $y_{t}^{N}$, because the Ramsey planner takes into account that in a competitive equilibrium the market for nontradables clears at all times.

The above equilibrium conditions look like a formidable set of constraints. Fortunately, it is possible to reduce the set of constraints considerably. In particular, it turns out that any processes $c_{t}^{T}$ and $d_{t+1}$ satisfy equilibrium conditions (17)-(23) if and only if they satisfy (17) and

$$
d_{t+1} \leq \kappa\left[y_{t}^{T}+\frac{1-a}{a}\left(\frac{c_{t}^{T}}{y_{t}^{N}}\right)^{\frac{1}{\xi}} y_{t}^{N}\right]
$$

To see this, suppose $c_{t}^{T}$ and $d_{t+1}$ satisfy (17) and (25). We must establish that (17)-(23) are also satisfied. Obviously, the resource constraint (17) holds. Now pick $p_{t}$ to satisfy (21). This is possible, because the process $c_{t}^{T}$ is given. Now use (21) to eliminate $p_{t}$ from (18). The resulting expression is (25), establishing that (18) holds. Next, pick $\lambda_{t}$ to satisfy (19). Now, set $\mu_{t}=0$ for all $t$. It follows immediately that the slackness condition (22) and the non-negativity condition (23) are satisfied. Finally, pick $\tau_{t}$ to ensure that (20) holds, that is,

$$
\tau_{t}=1-\beta\left(1+r_{t}\right) \mathbb{E}_{t} \frac{U^{\prime}\left(A\left(c_{t+1}^{T}, y_{t+1}^{N}\right)\right) A_{1}\left(c_{t+1}^{T}, y_{t+1}^{N}\right)}{U^{\prime}\left(A\left(c_{t}^{T}, y_{t}^{N}\right)\right) A_{1}\left(c_{t}^{T}, y_{t}^{N}\right)}
$$

Next, we need to show the reverse statement, that is, that processes $c_{t}^{T}$ and $d_{t+1}$ that satisfy (17)-(23) also satisfy (17) and (25). Obviously, (17) is satisfied. Combining (18) with (21) yields (25). This completes the proof of the equivalence of the constraint sets (17)-(23) and (17) and (25).

A discussion of why the Lagrange multiplier $\mu_{t}$ can be taken to be nil at all times in the above proof is in order. First, it is important to note that $\mu_{t}$ is the Lagrange multiplier associated with the individual household's collateral constraint, not the Ramsey planner's. The multiplier $\mu_{t}$ can be nil even if for the country as a whole the shadow value of collateral is strictly positive. Second, the result that $\mu_{t}$ can be chosen to be nil at all times does not mean that the collateral constraint will never bind in equilibrium. It simply means that the policymaker can pick the capital control policy in such a way that when the collateral constraint binds, individual agents feel that they would make the same debt choice whether 
they were constrained by the collateral restriction or not. That is, the collateral constraint binds but individually, given the taxes they face, households do not feel restricted thereby.

The Lagrange multiplier, $\mu_{t}$, need not be zero at all times. In particular, we could have picked a tax policy such that the private sector's Lagrange multiplier $\mu_{t}$ is positive in states in which the collateral constraint binds. In other words, $\mu_{t}$ and $\tau_{t}$ are indeterminate in states in which the collateral constraint is binding in equilibrium. The proof of this result is straightforward: if the collateral constraint binds, then the slackness condition (22) is satisfied regardless of the value of $\mu_{t}$. In addition, the Euler equation (20) features both $\tau_{t}$ and $\mu_{t}$, so any combination of these two variables that makes this equation hold and that satisfies $\mu_{t} \geq 0$, given the process $\lambda_{t}$ represents a solution. None of the remaining equilibrium conditions from the set (17)-(23) contains either $\mu_{t}$ or $\tau_{t}$, so this completes the proof that $\mu_{t}$ and $\tau_{t}$ are indeterminate in states in which the collateral constraint binds.

We can then state the Ramsey problem $\mathrm{as}^{2}$

$$
\max _{\left\{c_{t}^{T}, d_{t+1}\right\}} \mathbb{E}_{0} \sum_{t=0}^{\infty} \beta^{t} U\left(A\left(c_{t}^{T}, y_{t}^{N}\right)\right)
$$

subject to $c_{t}^{T}>0$

$$
c_{t}^{T}+d_{t}=y_{t}^{T}+\frac{d_{t+1}}{1+r_{t}}
$$

and

$$
d_{t+1} \leq \kappa\left[y_{t}^{T}+\frac{1-a}{a}\left(\frac{c_{t}^{T}}{y_{t}^{N}}\right)^{\frac{1}{\xi}} y_{t}^{N}\right]
$$

Note that the constraints of the Ramsey planner's problem may not be a convex set. That is, if two pairs $\left(c_{t}^{T}, d_{t+1}\right)$ satisfy both constraints given $d_{t}$, then a linear combination of these two pairs may not. This is because the right-hand side of the second constraint is convex in $c_{t}^{T}$ for $\xi<1$. Nonetheless, generically, the Ramsey allocation is unique because it is the outcome of a maximization problem.

An important characteristic of the above maximization problem is that the Ramsey planner internalizes the pecuniary externality. That is, he understands that individual consumption of tradables affects the relative price of nontradables, $p_{t}$, and therefore also the value of collateral. This is evident from the fact that $c_{t}^{T}$ appears on the right-hand side of the second constraint. This means that endowing the Ramsey planner with a single distorting

\footnotetext{
${ }^{2}$ The Ramsey problem is time consistent. This is because in any given period $t$, the constraints, (17) and (25), involve only variables that are either predetermined in period $t\left(d_{t}\right)$, exogenous $\left(y_{t}^{T}, y_{t}^{N}, r_{t}\right)$, or chosen in period $t\left(c_{t}^{T}, d_{t+1}\right)$, but they do not involve endogenous variables that will be determined in future periods. By contrast, in models in which assets serve as collateral the Ramsey problem does suffer from a time inconsistency problem as pointed out by Bianchi and Mendoza (forthcoming) and Jeanne and Korinek (2010).
} 
policy instrument, namely, the capital control tax $\tau_{t}$, allows him to induce agents to fully internalize the pecuniary externality.

Given the Ramsey allocation $\left\{c_{t}^{T}, d_{t+1}\right\}$, one can obtain the relative price of nontradables in the associated competitive equilibrium, $p_{t}$, from equation (21) and the private marginal utility of wealth, $\lambda_{t}$, from equation (19).

If the collateral constraint is binding, then, as discussed above, $\tau_{t}$ is indeterminate. Because, the household's Lagrange multiplier on the collateral constraint, $\mu_{t}$, must be nonnegative, $\mu_{t} \geq 0$, equation (20) implies that $\tau_{t}$ is bounded above by the right-hand-side of (26), which is less than one, implying a tax rate less than one hundred percent. In principle, the Ramsey planner could subsidize borrowing $\left(\tau_{t}<0\right)$, as in those states the collateral constraint is what determines the amount of borrowing and the value of $\tau_{t}$-provided it is less than the upper bound-is irrelevant.

In states in which the collateral constraint is slack under the Ramsey allocation, the Ramsey optimal capital control tax, $\tau_{t}$ is given by (26). Alternatively, one can express the optimal capital control tax in terms of the Ramsey planner's Lagrange multipliers on the resource and collateral constraints, respectively, as in Bianchi (2011). Under some regularity conditions, the optimal capital control tax satisfies $\frac{1}{1-\tau_{t}}=\frac{\mathbb{E}_{t} \lambda_{t+1}^{R}}{\mathbb{E}_{t} \lambda_{t+1}}$, where $\lambda_{t}^{R}>0$ is the Lagrange multiplier of the Ramsey planner on the resource constraint (17). ${ }^{3}$ One can show that $0<\lambda_{t}=\left(1-\mu_{t}^{R} \Psi_{t}\right) \lambda_{t}^{R} \leq \lambda_{t}^{R}$, where

$$
\Psi_{t} \equiv \kappa \frac{1-a}{a} \frac{1}{\xi}\left(\frac{c_{t}^{T}}{y_{t}^{N}}\right)^{1 / \xi-1}>0
$$

denotes the partial derivative of the value of collateral with respect to consumption of tradables and $\mu_{t}^{R} \geq 0$ denotes the Lagrange multiplier on the collateral constraint of the Ramsey planner. Therefore we can express the optimal capital control tax in states in which the collateral constraint is slack as

$$
\frac{1}{1-\tau_{t}}=\frac{\mathbb{E}_{t} \lambda_{t+1}^{R}}{\mathbb{E}_{t} \lambda_{t+1}^{R}\left(1-\mu_{t+1}^{R} \Psi_{t+1}\right)} .
$$

This expression provides several important insights. First, when the collateral constraint is slack in the current state and in all immediate successor states to the current state, that is, when $\mu_{t+1}^{R}=0$ in all states following the current state, then the optimal capital control tax in the current state is zero, $\tau_{t}=0$. Second, this expression says that when the collateral constraint is slack in period $t$ under the Ramsey allocation, then the optimal capital control tax is bounded below by zero. This follows from the fact that $0<\lambda_{t} \leq \lambda_{t}^{R}$. Third, the fact

\footnotetext{
${ }^{3}$ See the appendix for a detailed derivation of this expression.
} 
that $\tau_{t} \geq 0$ proves that the pecuniary externality induced by the collateral constraints calls for positive capital control taxes on average - as long as the collateral constraint is binding in some states in the ergodic distribution of the Ramsey optimal allocation. Thus one can infer from equation (28) that optimal capital controls are macroprudential in the sense that they are positive on average. Finally, an implication of the fact that optimal capital control taxes are bounded below by zero and positive on average is that the interest rate faced by households in the economy with optimal capital control taxes, $\left(1+r_{t}\right) /\left(1-\tau_{t}\right)$, is greater or equal than the interest rate faced by households in the unregulated economy. This suggests that debt should be lower in the Ramsey economy than in the unregulated economy, that is, the unregulated economy should display overborrowing relative to the Ramsey economy.

The focus of the present paper, however, is to characterize the cyclical properties of optimal capital controls, with an eye on ascertaining whether they are used in a countercyclical fashion, that is, increased during good times and lowered during bad times. Suppose that in the current state the collateral constraint is slack and there are some immediate successor states in which it will bind. We have just shown that in such a state the tax rate is given by (28) and thus is positive, that is, $\tau_{t}>0$. Consider now a negative shock to the endowment with the property that the collateral constraint in the current period remains slack. Then the Ramsey optimal tax rate continues to be given by (28). To first order, the response of $\tau_{t}$ is of the same sign as the response of the expected value of $\mu_{t+1}^{R} \Psi_{t+1}$. The negative endowment shock should, by the permanent income hypothesis, be associated with higher debt and a decline in the current absorption of tradables. With more debt, it seems intuitive that the Lagrange multiplier on the collateral constraint next period, $\mu_{t+1}^{R}$, should be higher or should be positive in more states in period $t+1$. Thus, if $\Psi_{t+1}$ were unchanged, then expression (28) suggests that a negative endowment shock in the current period is associated with an increase in $\tau_{t}$, that is to say optimal capital control policy is procyclical. Yet, $\Psi_{t+1}$ also responds to the negative endowment shock. In particular, if consumption of tradables, $c_{t+1}^{T}$, is expected to contract by more than consumption of nontradables, $y_{t+1}^{N}$, then, provided $\xi<1, \Psi_{t+1}$ will fall, offsetting the increase in $\mu_{t+1}^{R}$. For example, suppose that the endowment of nontradables is constant, a case considered in the numerical analysis of section 5 below. In this case a negative endowment shock in the current state would lead to a decline in $c_{t+1}^{T}$ and hence to a decline in $\Psi_{t+1}$. On the other hand, if both $y_{t}^{T}$ and $y_{t}^{N}$ were stochastic, persistent, and positively correlated, then a decline in the endowments in the current state should be associated with a decline in both $c_{t+1}^{T}$ and $y_{t+1}^{N}$ dampening the decline in $\Psi_{t+1}$. Thus, in that economy, the optimal capital control tax should be more procyclical than in an otherwise identical economy with a constant endowment of nontradables. Overall, the above discussion of the Ramsey condition (28) suggests that the optimal capital control tax 
is more likely to be procyclical than countercyclical. To provide a more precise assessment, we will solve for the equilibrium dynamics of the present economy. As they cannot be derived analytically for empirically realistic stochastic driving processes we will we resort to a quantitative analysis.

\section{Is Optimal Capital Control Policy Countercyclical?}

The baseline calibration of the model follows exactly the one in Bianchi (2011), which assumes that the economy is driven by endowment shocks. In section 5, we consider an alternative shock structure in which business cycles are driven by tradable-endowment and interest-rate shocks.

The time unit is one year. The natural logarithms of the traded and nontraded endowments are assumed to follow a bivariate AR(1) process. This process is estimated on annual, HP-filtered Argentine data spanning the period 1965 to 2007. The process takes the form

$$
\left[\begin{array}{c}
\ln y_{t}^{T} \\
\ln y_{t}^{N}
\end{array}\right]=\left[\begin{array}{cc}
0.901 & -0.453 \\
0.495 & 0.225
\end{array}\right]\left[\begin{array}{l}
\ln y_{t-1}^{T} \\
\ln y_{t-1}^{N}
\end{array}\right]+\epsilon_{t} ; \quad \epsilon_{t} \sim N\left(\emptyset,\left[\begin{array}{cc}
0.00219 & 0.00162 \\
0.00162 & 0.00167
\end{array}\right]\right)
$$

where $\epsilon_{t}$ is assumed to be i.i.d. This process implies unconditional standard deviations of 6 percent and serial correlations of about 0.5 for both endowments, and a contemporaneous correlation of 0.8 .

Following Bianchi (2011), we discretize the above driving process using 4 distinct values for $\ln y_{t}^{T}$ and 16 distinct pairs $\left(\ln y^{T}, \ln y^{N}\right)$. The endogenous state, $d_{t} /(1+r)$, is discretized using 800 evenly spaced points ranging from 0.4 to 1.02 . The interest rate is assumed to be constant and equal to 4 percent per year. The subjective discount factor, $\beta$, is set at 0.91 . Thus, $\beta(1+r)=0.9464$, which implies that agents are quite impatient relative to the market interest rate. This gives them a strong incentive to front load consumption by borrowing against future endowments. The remaining parameters are $\sigma=2, \xi=0.83, a=0.31$, and $\kappa=0.32(1+r)$. The value of $\kappa$ is not exactly the same as in Bianchi (2011), namely 0.32, because we specify the collateral constraint as $d_{t+1} \leq \kappa\left(y_{t}^{T}+p_{t} y_{t}^{N}\right)$, whereas Bianchi uses the specification $d_{t+1} /(1+r) \leq \kappa\left(y_{t}^{T}+p_{t} y_{t}^{N}\right)$. Setting $\kappa$ to $0.32(1+r)$ in the present model makes both calibrations equivalent. Table 1 summarizes the calibration and the discretization of the state space. We solve the unregulated equilibrium by an Euler-equation iteration procedure and the Ramsey equilibrium by value function iteration.

As shown in section 3, the Ramsey optimal capital control tax rate, $\tau_{t}$, is indeterminate when the collateral constraint is binding. In this case, we set $\tau_{t}$ to "Not a Number" (NaN). 
Table 1: Calibration of the Economy with Endowment Shocks

\begin{tabular}{ccl}
\hline \hline Parameter & Value & Description \\
\hline$\kappa$ & 0.3328 & Parameter of collateral constraint \\
$\sigma$ & 2 & Inverse of intertemporal elast. of subst. \\
$\beta$ & 0.91 & Subjective discount factor \\
$r$ & 0.04 & Interest rate (annual) \\
$\xi$ & 0.83 & Intratemporal elast. of subst. \\
$a$ & 0.31 & Weight on tradables in CES aggregator \\
$y^{N}$ & 1 & Steady-state nontradable output \\
$y^{T}$ & 1 & Steady-state tradable output \\
$n_{y}$ & 16 & Number of grid points for $\left(\ln y_{t}^{T}, \ln y_{t}^{N}\right)$ \\
$n_{d}$ & 800 & Number of grid points for $d_{t}$, equally spaced \\
{$\left[\ln \underline{y}^{T}, \ln \bar{y}^{T}\right]$} & {$[-0.1093,0.1093]$} & Range for tradable output \\
{$\left[\ln \underline{y}^{N}, \ln \bar{y}^{N}\right]$} & {$[-0.1328,0.1328]$} & Range for nontradable output \\
{$[\underline{d} /(1+r), \bar{d} /(1+r)]$} & {$[0.41 .02]$} & Range for debt \\
\hline \hline Note. The time unit is one year. The calibration is taken from Bianchi $(2011)$.
\end{tabular}

That is, we assign a numerical value to the optimal capital control tax only in states in which it is uniquely determined.

\subsection{Optimal Capital Controls During Boom-Bust Cycles}

We start by examining the behavior of optimal capital controls and macroeconomic indicators of interest around boom-bust episodes. That is, episodes in which a large expansion in aggregate activity is followed by a large contraction. The question we wish to address is whether the Ramsey planner curbs the expansion in aggregate demand by raising capital controls during the boom phase and fosters absorption by lowering capital controls during the contractionary phase.

We define a boom-bust episode as a situation in which tradable output starts above trend and is below trend three years later. The assumed discretized endowment process implies that the economy is on average 5 percent above trend at the peak of the boom and 5 percent below trend at the trough of the bust. This is a large contraction. The standard deviation of the log of traded output is 5.6 percent. Thus, from peak to trough tradable output contracts by 1.7 standard deviations.

To characterize the typical boom-bust cycle, we simulate the endowment process for one million years and extract all windows containing a boom-bust cycle. This yields 12 non-overlapping boom-bust episodes every century. We refer to the average dynamics of 
an economy over all boom-bust episodes as the typical boom-bust cycle. We use the same sequence of one-million realizations of the endowments and the same initial level of debt to simulate one million years of data from the unregulated economy (i.e., the economy with $\tau_{t}=0$ for all $t$ ) and from the economy with Ramsey optimal capital control taxes.

Figure 1 displays with solid lines the dynamics of the unregulated economy during the typical boom-bust cycle. The exogenous boom-bust cycle in tradable output produces endogenous boom-bust cycles in total output $\left.\left(y_{t} \equiv y_{t}^{T}+p_{t} y_{t}^{N}\right)\right)$, consumption, the relative price of nontradables, and the value of collateral. External debt, by contrast, is remarkably flat. The lack of response of external debt to large swings in the endowments is driven primarily by the fact that agents are highly impatient. So much so that the consumption smoothing motive is dominated by the desire to front load consumption. Although the contraction of the economy from peak to trough is quite large, the collateral constraint remains slack throughout the typical boom-bust cycle. Only fifteen percent of the boom-bust episodes end in a financial crisis.

The figure displays with broken lines the behavior of the economy over the typical boombust cycle under the Ramsey-optimal capital-control policy. The predicted booms and busts in output and consumption of tradable goods are remarkably similar in the unregulated and the Ramsey economies. This suggests that the pecuniary externality induces little amplification when the collateral constraint is slack.

The Ramsey planner moves capital controls significantly over the typical boom-bust cycle (bottom-right panel of figure 1). ${ }^{4}$ For this variable we report the median value rather than the mean value because we found that its distribution is skewed. The unconditional mean of the tax rate is 4.2 percent and the unconditional median of the tax rate is only 2.5 percent. The figure shows that the movements in capital controls do not follow a countercyclical pattern. On the contrary, during the boom phase of the cycle capital controls are lowered from 2.5 to 0.6 percent, and during the bust phase of the cycle they are increased to 6.3 percent. We interpret these predicted dynamics as suggesting that in the present model the collateral constraint does not call for tightening capital controls during booms as a prudential measure. Instead, the prescription of the Ramsey plan is to wait until the economy is in a recession before starting to discourage external borrowing via increases in capital controls.

\footnotetext{
${ }^{4}$ As mentioned above, because the tax rate is indeterminate when the collateral constraint is binding under the Ramsey policy, in the numerical analysis the capital control tax is given a number only when the collateral constraint is slack under the Ramsey policy.
} 
Figure 1: The Typical Boom-Bust Cycle
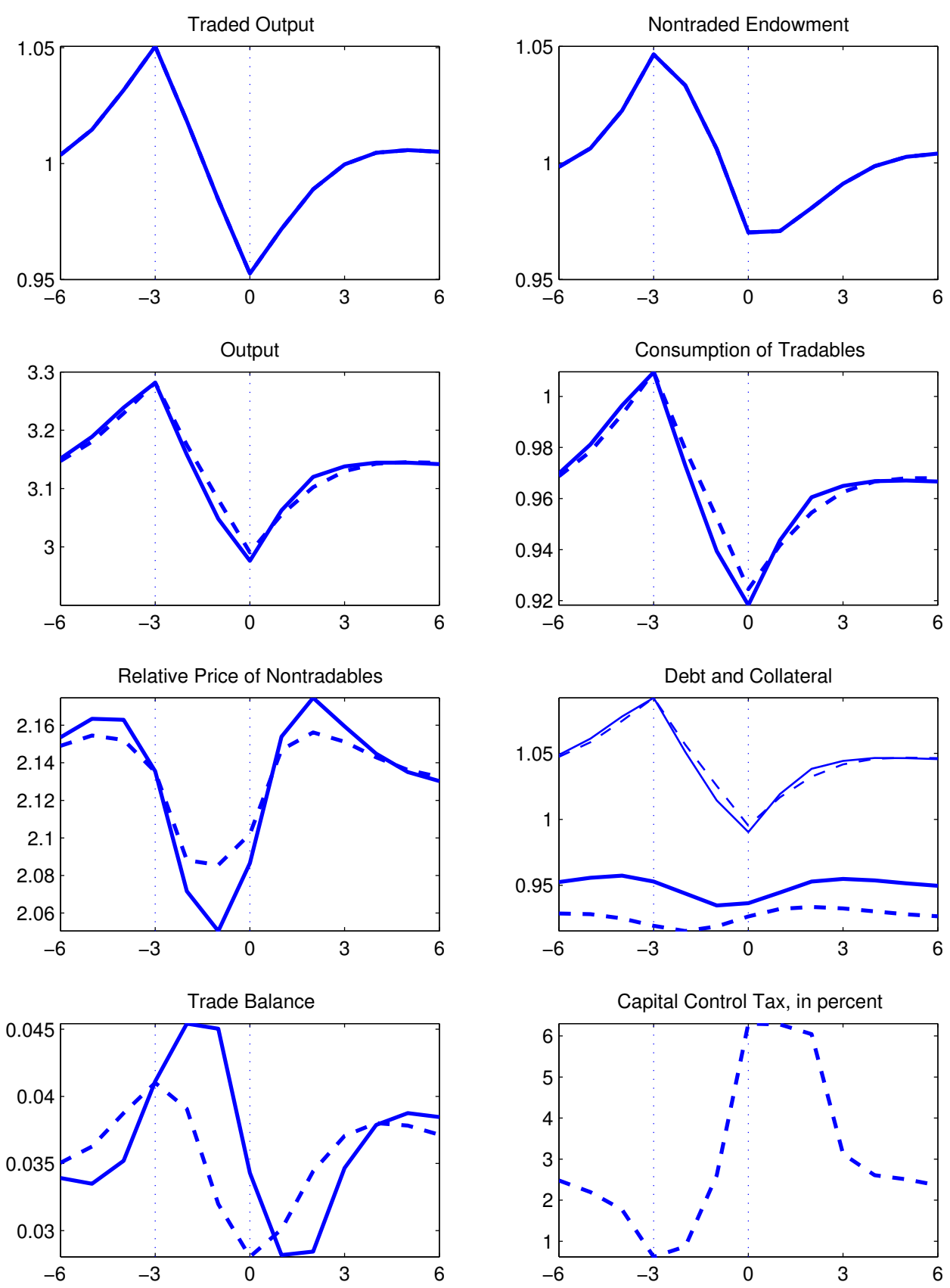

: unregulated economy

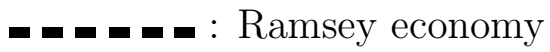

Note. Each line is the mean across all windows containing a boom-bust cycle in a time series of 1 million years. For the capital-control tax rate, the figure displays the median instead of the mean across windows because this variable is skewed, with an unconditional mean of 4.2 percent and an unconditional median of 2.5 percent. Because, as shown in section 3, the capital control tax rate is indeterminate when the collateral constraint binds under the Ramsey policy, this variable is given a number only if the collateral constraint is slack under the Ramsey policy. Replication file typical_boom_bust.m in sgu_endowment_shocks.zip. 
Table 2: Debt, Frequency of Crises, and Optimal Capital Controls

\begin{tabular}{lcccccc}
\hline \hline Environment & \multicolumn{2}{c}{ Debt-to-Output Ratio } & \multicolumn{2}{c}{ Frequency of Crises } & \multicolumn{2}{c}{ Optimal Capital Controls } \\
\cline { 2 - 6 } & Unregulated & Ramsey & Unregulated & Ramsey & median $\left(\tau_{t}\right)$ & $\operatorname{corr}\left(\tau_{t}, y_{t}\right)$ \\
\hline$y_{t}^{T}$ and $y_{t}^{N}$ shocks & $29.2 \%$ & $28.5 \%$ & 12 years & 26 years & $2.5 \%$ & -0.8 \\
$y_{t}^{T}$ and $r_{t}$ shocks & $29.3 \%$ & $28.3 \%$ & 14 years & 37 years & $1.9 \%$ & -0.1 \\
\hline \hline
\end{tabular}

Note. The debt-to-output ratio is the unconditional mean of $\frac{d_{t+1} /\left(1+r_{t}\right)}{y_{t}}$. The variable $y_{t} \equiv y_{t}^{T}+p_{t} y_{t}^{N}$ denotes output in terms of tradables. A crisis is defined as a period with a binding collateral constraint. The environment with $y_{t}^{T}$ and $y_{t}^{N}$ shocks is studied in section 4 and the environment with $y_{t}^{T}$ and $r_{t}$ shocks is studied in section 5. Because the capital control tax is indeterminate when the collateral constraint binds under the Ramsey policy, it is given a number only when the collateral constraint is slack under the Ramsey policy. Replication files: for line 1, table.m in sgu_endowment_shocks.zip, and for line 2, table.m in sgu_rshocks.zip.

\subsection{Optimal Capital Controls Around Financial Crises}

We have shown that optimal capital controls do not behave in a countercyclical manner during a typical boom-bust cycle. Another perspective to gauge whether optimal capital control policy is countercyclical is to consider the behavior of optimal capital controls during financial crises. To this end, we characterize the behavior of the unregulated and Ramsey economies around episodes in which the collateral constraint binds in the unregulated economy. As in the analysis of boom-bust cycles, we simulate the unregulated economy for one million years. We then extract all eleven-year windows centered around a period in which the collateral constraint binds. This yields 85,242 windows. Thus, the unregulated economy suffers on average one financial crisis every 12 years (table 2). We then use the same sequence of one-million realizations of the exogenous states and the same initial level of debt to simulate one million years of data from the Ramsey economy. Over these one million periods, the Ramsey economy experiences 38,617 episodes of a binding constraint. This means that the Ramsey optimal capital control policy cuts the frequency of financial crises from once every 12 years to once every 26 years (table 2 ). It follows that the pecuniary externality makes the economy more vulnerable to financial crises.

Figure 2 displays with a solid line the mean across all 85,242 windows in which the unregulated economy suffers a crisis. We refer to these average dynamics as the typical financial crisis implied by the present model economy. In the figure, the time of the crisis is normalized to period 0 . The crisis occurs after a string of increasingly negative endowment shocks. In the period of the crisis, both endowments are about 8 percent below average.

The run-up to the crisis does not feature an unusually large accumulation of debt. Between periods -5 and -1 , external debt does increase, but not significantly (less than half a 
Figure 2: The Typical Financial Crisis
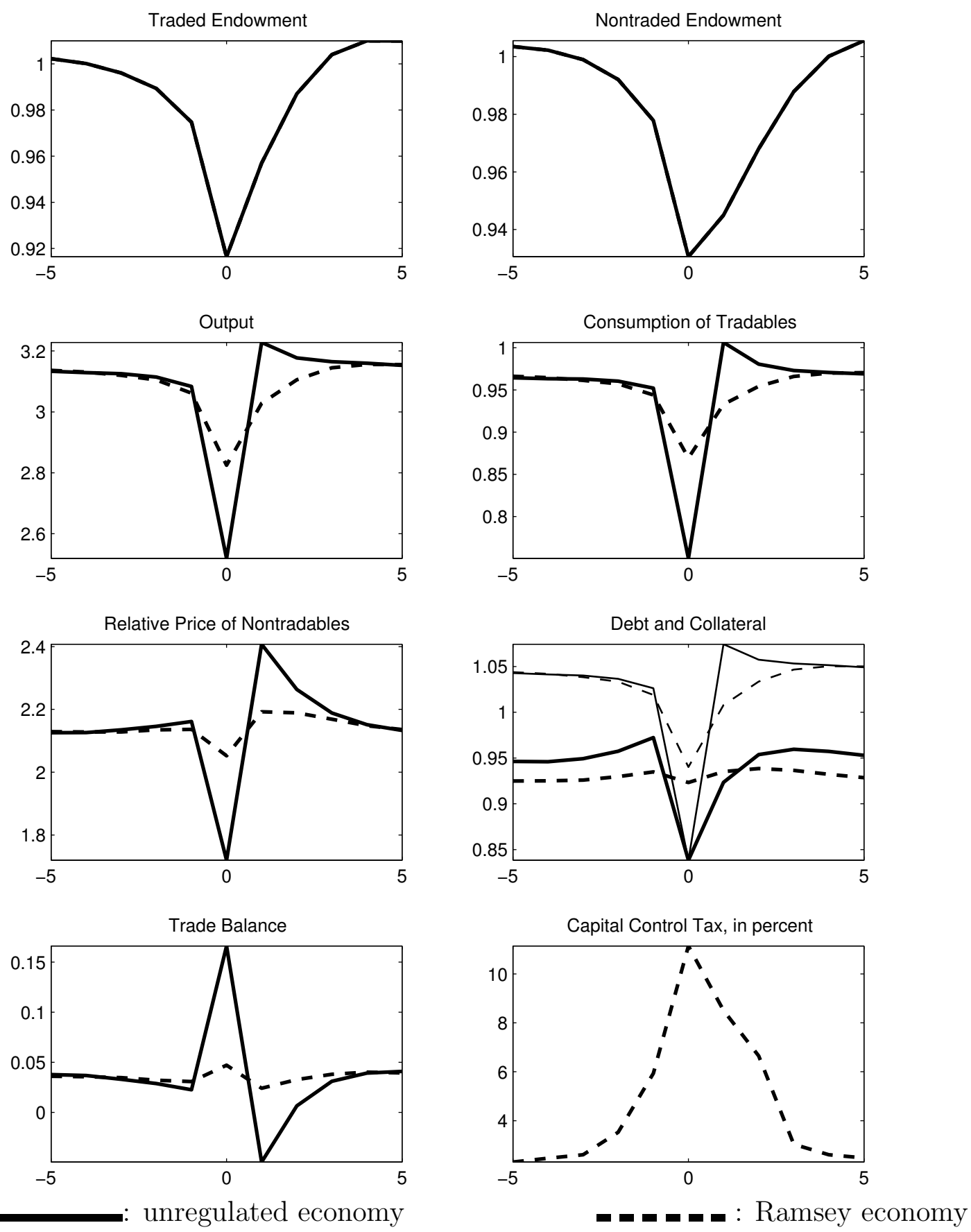

Note. Each line is the mean across all 11-year windows containing a binding collateral constraint in the center in a one-million-year time series from the unregulated economy. For the capitalcontrol tax rate, the figure displays the median instead of the mean across windows because this variable is skewed, with an unconditional mean of 4.2 percent and an unconditional median of 2.5 percent. Because, as shown in section 3, the capital control tax rate is indeterminate when the collateral constraint binds under the Ramsey policy, this variable is given a number only if the collateral constraint is slack under the Ramsey policy. Replication file typical_crisis.m in sgu_endowment_shocks.zip. 
standard deviation). Thus, the typical financial crisis in the present model does not capture well the narrative that financial crises are preceded by externally financed credit booms. However, the typical crisis predicted by the model does bear some of the signs of a sudden stop. Consumption of tradables contracts by more than output causing a large improvement in the trade balance of more than 10 percent of tradable output. At the time of the crisis, the economy deleverages, with external debt falling by about 15 percent. This sharp reduction in external liabilities requires a similarly large contraction in aggregate absorption, which in turn causes a Fisherian deflation, with the relative price of nontradables falling by 20 percent. The Fisherian deflation aggravates the fall in collateral, which is already quite depressed by the fall in both endowments.

Although the financial crisis is quite severe, it is short lived. Just one period after the crisis the economy is above steady state and the trade balance reverses sign from a large surplus to a deficit. Interestingly, this quick recovery happens in a context in which both endowments are still more than 5 percent below average. The reason for the swift recovery is that the deleveraging that occurs in period 0 places the economy in a sound financial position in period 1. In particular, with low levels of debt at the beginning of period 1, households can afford a higher level of absorption of all goods traded and nontraded. In turn, the fact that the endowment of nontradables is still quite depressed implies that its price must increase to ensure market clearing. The relative price of nontradables overshoots from 20 percent below mean in period 0 to 13 percent above mean in period 1 . This large real appreciation increases the value of collateral and loosens the collateral constraint. These predicted dynamics are at odds with a growing empirical literature that finds that financial crises are associated with slow recoveries (see, for example, Cerra and Saxena, 2008; Reinhart and Reinhart, 2010; and Reinhart and Rogoff, 2014).

How does the Ramsey planner handle situations that, in the absence of policy intervention, end up in crises? Figure 2 displays with broken lines the implied dynamics under the Ramsey-optimal capital control policy. The optimal capital control policy manages to fend off the typical crisis. The right panel on the third row of the figure shows with a thin broken line the value of collateral, $\kappa\left(y_{t}^{T}+p_{t} y_{t}^{N}\right)$, under the Ramsey policy and with a thick broken line the level of external debt assumed in period $t, d_{t+1}$, under the Ramsey policy. In both the Ramsey and the unregulated economies collateral falls sharply in period 0 due to the collapse in both endowments. However, the Ramsey economy is less exposed to external debt than its unregulated counterpart, and therefore displays more slack in the collateral constraint. As a result, the fall in collateral due to the fall in endowments does typically not end up in a binding collateral constraint in the Ramsey economy. This, in turn, implies that this economy does not suffer a Fisherian deflation with its negative feedback on the value of 
collateral. Indeed, the left panel of row 3 of the figure shows that under the Ramsey policy the relative price of nontradables is little changed in period 0 . The Ramsey planner manages to arrive at period 0 with less debt by a capital control policy whose long-run and cyclical properties are conducive to avoiding a binding constraint in recessions. Specifically, capital controls are positive on average (the median value of $\tau_{t}$ is 2.5 percent), which implies that on average, the Ramsey economy has 2.3 percent (or 0.7 percent of output) less debt than the unregulated economy (see table 2). This appears to be a small difference, but it is finely calculated by the Ramsey planner to avoid a binding constraint. The Ramsey-optimal policy trades off the desire of impatient households to front-load consumption and accumulate debt against avoiding a binding collateral constraint.

The capital control policy displays significant movements around the financial crisis. The Ramsey planner increases capital controls as the economy enters in recession to discourage the build up of debt. As the economy falls into an increasingly deep recession prior to period 0 , the capital-control tax rate increases from 2.3 percent in period -5 to 11 percent in period 0 . In this regard, the optimal capital-control policy is not countercyclical in nature. As in the case of boom-bust cycles, the planner waits until the economy has entered into the recession before increasing capital controls.

The conclusion that optimal capital-control policy is not countercyclical in open economies with a pecuniary externality due to collateral constraints holds not only for large boom-bust cycles or financial crises but also over regular business cycles. As shown in table 2, the unconditional correlation of the optimal capital-control tax with output is -0.8 . Thus, the Ramsey planner lowers capital controls during expansions and raises them during contractions.

\section{Interest-Rate Shocks and the Cyclicality of Optimal Capital-Control Policy}

Thus far, we have considered an economy driven purely by endowment shocks. We found that in the context of that environment the cyclical component of optimal capital control policy is not countercyclical, for the Ramsey planner increases capital controls when the economy is in recession and lowers them when the economy is expanding. We now change the stochastic environment by introducing interest-rate shocks. The rationale for introducing this type of shock is twofold. First, movements in the world interest rate and in country spreads, the two components of the country interest rate, have been shown to be an important driver of business cycles in emerging countries (Uribe and Yue, 2006). Second, in principle, there are reasons to imagine that interest-rate shocks may have a significant effect on the cyclical 
properties of optimal capital control policy. During periods of low interest rates, households have an incentive to increase consumption and to borrow more. The expansion in aggregate absorption pushes up the price of nontradables, raising the value of collateral, and thereby making room for the expansion in external borrowing. At the end of this phase of low interest rates, the economy is more leveraged and therefore more vulnerable to negative shocks. In this environment, the Ramsey planner may have an incentive to put sand in the wheels of capital flows during periods of low interest rates, to avoid a rough landing in the contractionary phase of the cycle. The purpose of this section is to ascertain whether this intuition actually plays out when we feed the model with a realistic process for the country interest rate.

The structure of the model economy is unchanged, except that now the sources of uncertainty are the interest rate, $r_{t}$, and the endowment of tradables, $y_{t}^{T}$. The endowment of nontradables is assumed to be constant and normalized to unity, $y_{t}^{N}=y^{N}=1$ for all $t$. We assume that $y_{t}^{T}$ and $r_{t}$ follow a bivariate $\operatorname{AR}(1)$ process. Specifically, we annualize the quarterly process estimated in Schmitt-Grohé and Uribe (2016b). There, we use Argentine quarterly data over the period 1983:Q1 to 2001:Q4. ${ }^{5}$ The annual AR(1) representation is

$$
\left[\begin{array}{c}
\ln y_{t}^{T} \\
\ln \frac{1+r_{t}}{1+r}
\end{array}\right]=\left[\begin{array}{cc}
0.48 & -0.77 \\
-0.08 & 0.68
\end{array}\right]\left[\begin{array}{c}
\ln y_{t-1}^{T} \\
\ln \frac{1+r_{t-1}}{1+r}
\end{array}\right]+\epsilon_{t} ; \quad \epsilon_{t} \sim N\left(\emptyset,\left[\begin{array}{cc}
0.0031 & -0.0015 \\
-0.0015 & 0.0014
\end{array}\right]\right)
$$

and $r=0.1325$, where $\epsilon_{t}$ is assumed to be i.i.d. The average interest rate of 13.25 percent per year reflects the fact that Argentina faced high country premia over the estimation period. The estimated $\mathrm{AR}(1)$ process implies high volatilities of both the interest rate and the natural logarithm of tradable output, of 6.5 percentage points and 11.7 percent, respectively. ${ }^{6}$ Also, the interest rate and tradable output display negative comovement, with a contemporaneous correlation of -0.87 . This means that both variables reinforce their cyclical macroeconomic effects on aggregate demand. Periods of low interest rates tend to coincide with high levels of tradable endowment, both giving incentives for households to expand spending. Similarly, periods of high interest rates tend to be accompanied by low levels of tradable endowment, both inducing a contraction in aggregate demand.

We discretize the above process using 21 equally spaced points for the natural logarithm of $y_{t}^{T}$ and 11 equally spaced points for the natural logarithm of $\left(1+r_{t}\right) /(1+r)$ (see table 3 for

\footnotetext{
${ }^{5}$ The measure of traded output is value added in agriculture, forestry, fishing, mining, and manufacturing. The data source is INDEC. The cyclical component is obtained by removing a log-quadratic time trend.

${ }^{6}$ The implied process for traded output is twice as volatile as the one implied by (29). The explanation for this discrepancy is most likely the detrending method. Uribe and Schmitt-Grohé (2017, Chapter 1) show that the standard deviation of the cyclical component of Argentine annual GDP over the period 1960 to 2011 falls from 10.7 percent under log-quadratic detrending to 6.3 percent under HP-100 filtering.
} 
Table 3: Calibration of the Economy with Interest-Rate Shocks

\begin{tabular}{ccl}
\hline \hline Parameter & Value & Description \\
\hline$\kappa$ & 0.3328 & Parameter of collateral constraint \\
$\sigma$ & 2 & Inverse of intertemporal elast. of subst. \\
$\beta$ & 0.8357 & Subjective discount factor \\
$r$ & 0.1325 & Steady state country interest rate \\
$\xi$ & 0.83 & Intratemporal elast. of subst. \\
$a$ & 0.31 & Weight on tradables in CES aggregator \\
$y^{N}$ & 1 & Nontradable output \\
$y^{T}$ & 1 & Steady-state tradable output \\
$n_{y^{T}}$ & 21 & Grid points for ln $y_{t}^{T}$, equally spaced \\
$n_{r}$ & 11 & Grid points for ln $\left(\frac{1+r_{t}}{1+r}\right)$, equally spaced \\
$n_{d}$ & 800 & Grid points for $d_{t}$, equally spaced \\
{$\left[\ln \underline{y}^{T}, \ln \bar{y}^{T}\right]$} & {$[-0.3706,0.3706]$} & Range for tradable output \\
{$\left[\ln \left(\frac{1+\underline{r}}{1+r}\right), \ln \left(\frac{1+\bar{r}}{1+r}\right)\right]$} & {$[-0.2040,0.2040]$} & Range for interest rate \\
{$[\underline{d}, \bar{d}]$} & {$[-0.5,1.5]$} & Range for debt \\
\hline \hline
\end{tabular}

Note. The time unit is one year.

the respective ranges). The transition probability matrix is estimated using the simulation approach developed in Schmitt-Grohé and Uribe (2009). The calibration of the remaining parameters of the model is unchanged, except for the subjective discount factor, $\beta$. We set $\beta$ to preserve the relative impatience of the representative household in the endowment-shock economy, that is, to maintain the difference between the subjective and market discount rates assumed in the endowment-shock economy. Specifically, we calibrate $\beta$ so that $\beta(1+r)$ is the same in the present calibration and in the calibration of the endowment-shock economy. This requires setting $\beta$ equal to 0.8357 . This calibration choice ensures similar debt levels in both economies (see table 2). Table 3 summarizes the calibration of the present economy.

Figure 3 displays the dynamics of the unregulated and Ramsey-optimal economies over a typical boom-bust episode. Here we define a typical boom-bust episode as one in which tradable output starts below mean, is at least one standard deviation above mean three years later, and then falls to at least one standard deviation below mean in the subsequent three years. We are able to give a more precise definition of a boom-bust cycle than was possible in the endowment-shock economy because the discretization of the endowment is finer (21 versus 4 points). Because $y_{t}^{T}$ and $r_{t}$ are highly negatively correlated, we could have similarly defined a boom-bust cycle in terms of the interest rate. This is evident from the top panel of figure 3 .

The main message conveyed by the figure is that, as in the endowment-shock economy, optimal capital-control policy is not countercyclical. On the contrary, the Ramsey planner 
Figure 3: Interest-Rate Shocks and The Typical Boom-Bust Cycle
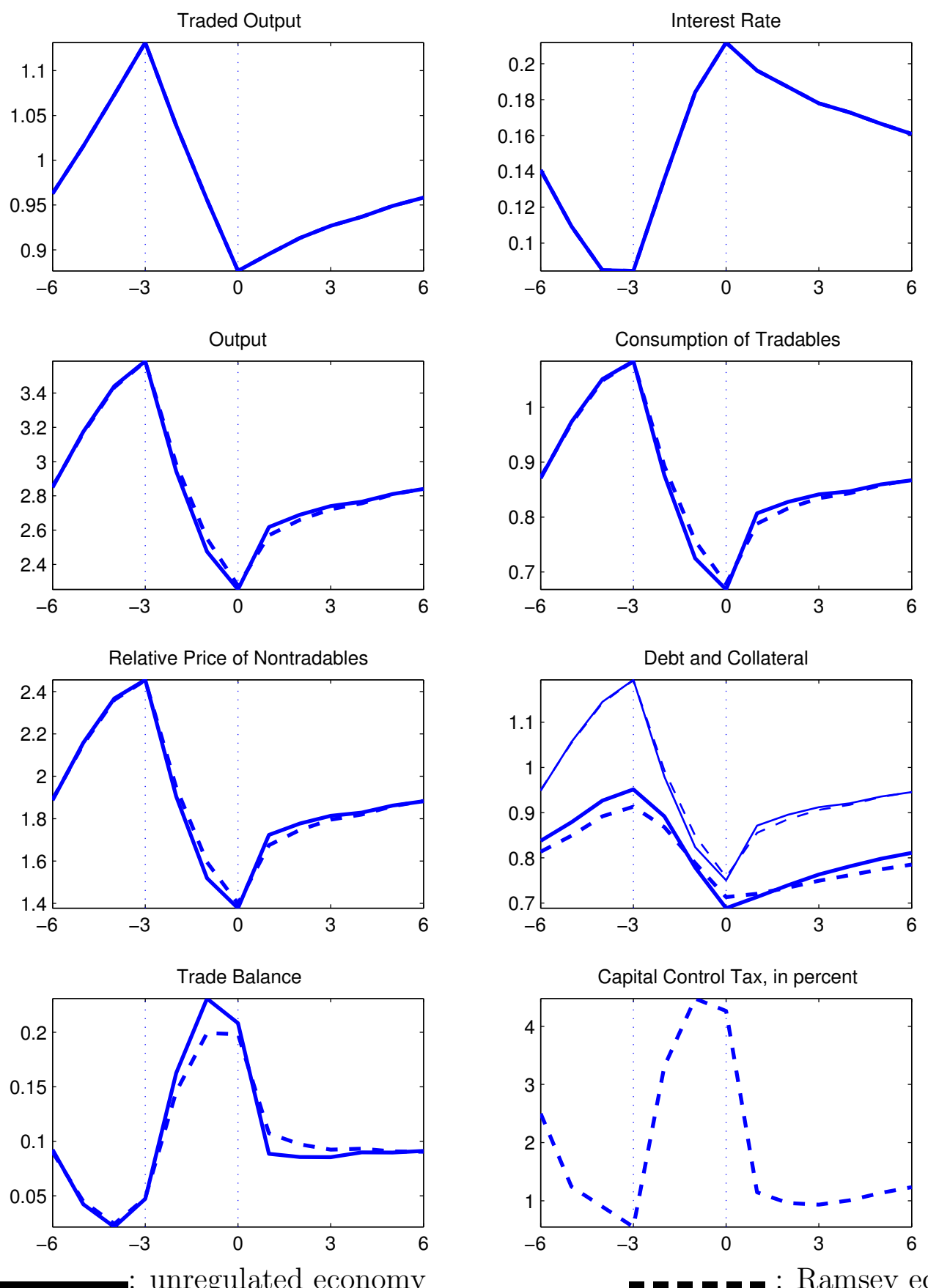

Note. Each line is the mean across all windows containing a boom-bust cycle in a time series of 1 million years. For the capital-control tax rate, the figure displays the median because the distribution of tax rates is skewed. The mean is 2.5 percent and the median is 1.9 percent. Because the capital control tax rate is indeterminate when the collateral constraint binds under the Ramsey policy, this variable is given a number only if the collateral constraint is slack under the Ramsey policy. Replication file typical_boom_bust.m in sgu_rshocks.zip. 
decreases capital controls during booms and increases them during contractions. In addition, as in the endowment-shock economy, the presence of the pecuniary externality has little effect on the boom-bust dynamics. The dynamics of the unregulated economy (i.e., the one with $\tau_{t}=0$ for all $t$ ) shown with a solid line are basically the same as the dynamics of economy with Ramsey optimal capital control policy, shown with a broken line. In this sense, the graph suggests that the pecuniary externality does not amplify boom-bust cycles in the economy with interest rate shocks either.

The Ramsey planner also takes a procyclical policy stands during financial crises. Figure 4 depicts the dynamics of a typical financial crisis in the interest-rate shock economy. As before, we define a financial crisis as a situation in which the collateral constraint binds. The typical financial crisis occurs after a combination of large adverse shocks to the country interest rate and tradable output. The country interest rate increases by almost 8 percentage points between periods -2 and 0 , and tradable output falls by about 12 percent in the same short period. A financial crisis occurs slightly less frequently than in the endowment-shock economy (once every 14 years versus once every 12 years; see table 2). As in the endowmentshock economy, a financial crisis is associated with a large contraction in traded absorption, a significant improvement in the trade balance, debt deleveraging, and a Fisherian deflation in the value of collateral as embodied in the sharp depreciation of the real exchange rate (i.e., the sharp fall in $p_{t}$ ).

An improvement of the present model over the endowment-shock economy is that now, in line with the data, financial crises are associated with a slow recovery. Five years after the crisis, output and consumption remain below trend and the real exchange rate remains depreciated. However, the reason for the slow recovery is not the presence of the collateral constraint, but the persistence of interest-rate shocks, which are fully exogenous. As in the endowment-shock economy, the deleveraging that occurs in period 0 puts the economy in a better financial standing in period 1, which is conducive to a quick recovery of aggregate demand. However, in the present environment interest rates remain high for a protracted period of time, which discourages spending and borrowing.

Figure 4 also displays the equilibrium dynamics under Ramsey-optimal capital-control policy, that is, when the pecuniary externality is fully internalized. Most of the time, the Ramsey planner manages to avoid financial crises. The frequency of financial crises falls from once every 14 years in the unregulated economy to once every 37 years under the Ramseyoptimal capital-control policy (table 2). As in the endowment-shock economy, the Ramsey planner achieves this reduction in the frequency of crises in two ways. First, the capital control tax rate is positive on average, with an unconditional median of 1.9 percent (table 2). As a consequence, agents borrow less than in the unregulated economy. The unconditional 
Figure 4: The Typical Financial Crisis in the Interest-Rate Economy
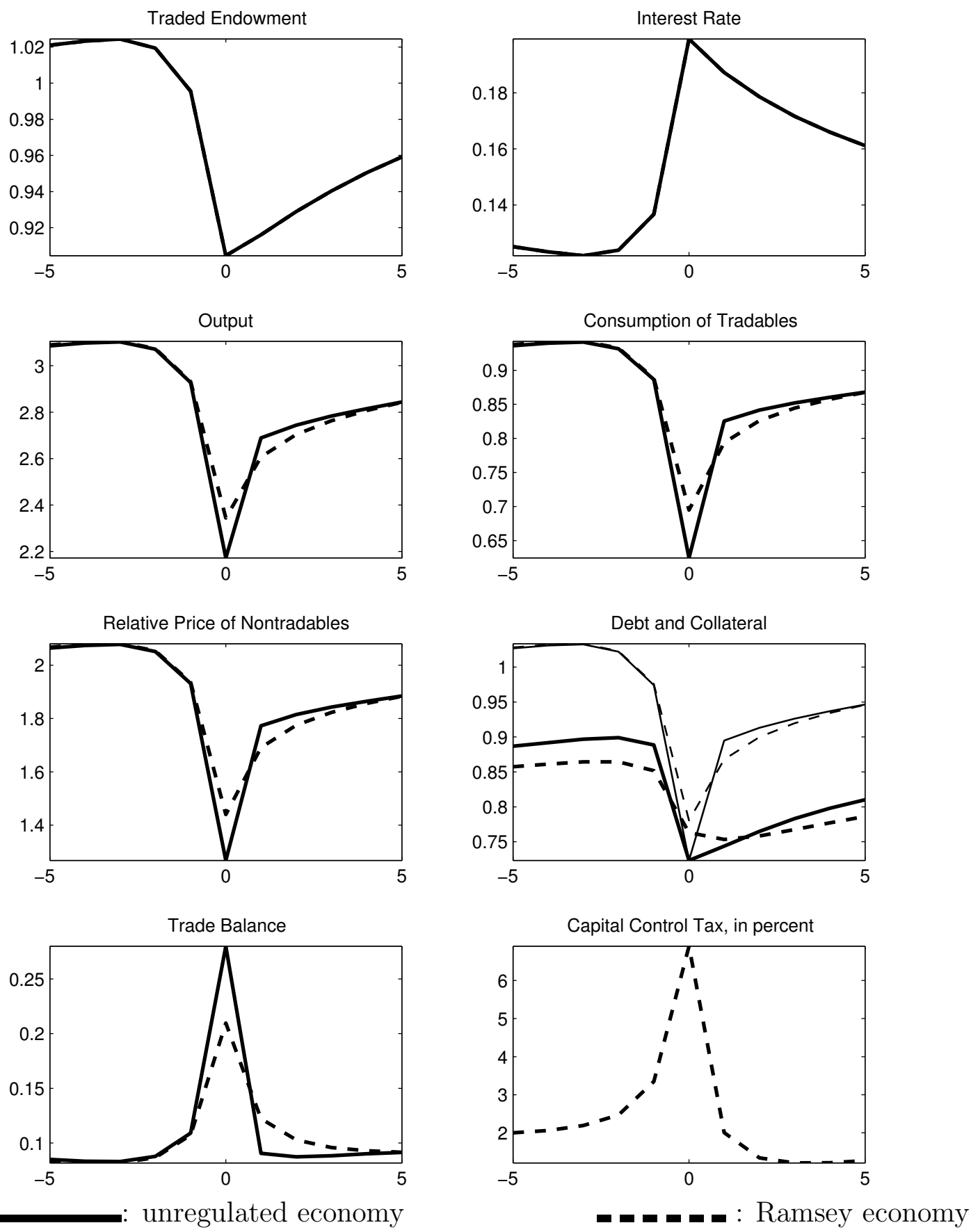

Note. Each line is the mean across all 11-year windows containing a binding collateral constraint in the center in a one-million-year time series from the unregulated economy. For the capital-control tax rate, the figure displays the median instead of the mean across windows because this variable is highly skewed. Because the capital control tax rate is indeterminate when the collateral constraint binds under the Ramsey policy, in the figure this variable is given a number only if the collateral constraint is slack under the Ramsey policy. Replication file typical_crisis.m in sgu_rshocks.zip. 
debt to output ratio is 28.3 percent compared to 29.3 percent in the unregulated economy (see again table 2). The lower average level of debt also has a positive effect on collateral. The reason is that less indebted households, by devoting a smaller fraction of their income to debt service, can enjoy a higher level of consumption, which in equilibrium boosts the price of nontradables, raising the collateral value of nontraded output. ${ }^{7}$

The second way in which the planner avoids financial crises is through the cyclical component of capital controls. Figure 4 shows that as the economy enters in a recession, the planner increases capital controls to discourage households from financing the fall in income by borrowing from the rest of the world. It follows that, as in the endowment-shock economy, capital control policy is not countercyclical in nature. The Ramsey planner waits until the economy is in recession to increase capital controls, as opposed to raising capital controls preemptively during booms to allow the economy to enter recessions with a lower debt burden.

The lack of countercyclicality of the optimal capital-control policy also holds unconditionally. The unconditional correlation of $\tau_{t}$ with $y_{t}^{T}+p_{t} y^{N}$ is -0.1 (table 2), which means that expansions in output are accompanied by reductions in capital-control taxes and vice versa. In the endowment-shock economy this correlation is more negative at -0.8 . The reason the negative correlation is smaller (in absolute value) in the present economy is the absence of shocks to the nontraded endowment. To see this, it is of use to look again at equation (28). In the economy with nontradable endowment shocks, $c_{t+1}^{T}$ and $y_{t+1}^{N}$ comove positively over the cycle. As a result, $\Psi_{t+1}$ is relatively acyclical. This means that the cyclicality of $\tau_{t}$ is governed by the cyclicality of $\mu_{t+1}^{R}$. By contrast, in the absence of shocks to the nontraded endowment, $\Psi_{t+1}$ inherits the cyclicality of $c_{t+1}^{T}$. Since $c_{t+1}^{T}$ and $\mu_{t+1}^{R}$ are negatively correlated, changes in $\Psi_{t+1}$ and $\mu_{t+1}^{R}$ tend to offset each other causing $\tau_{t}$ to be less cyclical. It is therefore reasonable to conjecture that allowing for nontradable endowment shocks in the present economy would result in a larger negative correlation between optimal capital controls and output.

In the preceding analysis the cyclicality of optimal capital controls is taken to be their conditional and unconditional correlations with output. A different dimension along which the cyclical nature of capital control policy is often discussed, especially in policy circles, has to do with the behavior of capital controls over the leverage cycle. For example, it is argued that an increase in the debt-to-output ratio triggered by a fall in the country interest rate should be met with a macroprudential increase in capital controls. It turns out

\footnotetext{
${ }^{7}$ It can be shown numerically that the average optimal capital-control tax rate and the frequency of crises are sensitive to the value assumed for the relative patience factor, $\beta(1+r)$. The closer the relative patience factor is to unity, the lower the average optimal capital-control tax rate and the frequency of crises will be.
} 
that in the present model the unconditional correlation between the debt-to-output ratio, $d_{t+1} /\left(y_{t}^{T}+p_{t} y_{t}^{N}\right)$, and the optimal capital control tax, $\tau_{t}$, is indeed positive at 0.7 . However, this positive correlation does not conform with the intuition given above, for in the present model the debt-to-output ratio tends to be high not in periods in which the interest rate is low, but in periods in which it is high. Specifically, the correlation between $d_{t+1} /\left(y_{t}^{T}+p_{t} y_{t}^{N}\right)$ and $r_{t}$ is positive at 0.4 . This is a further manifestation of the model's prediction that optimal capital controls are high when the economy is in recession, or equivalently, that optimal capital control policy is procyclical.

\section{Conclusion}

This paper shows that the conventional view according to which policymakers should increase capital controls during economic booms and loosen them during contractions is not supported as a Ramsey optimal outcome in open economy models with pecuniary externalities due to flow collateral constraints. It shows that in this class of models, the Ramsey planner waits until recessions have set in before increasing capital controls, as opposed to raising capital controls preemptively during booms to ensure that the economy enters the contractionary phase of the business cycle with sound financial fundamentals.

To understand the logic behind the optimality of a procyclical capital control policy in the context of the present economy, it is important to understand that a key ingredient of most models in this class is the assumption of high impatience on the part of households. For example, in the present calibration, which is a typical one, the relative impatience factor, $\beta(1+r)$, is 0.95 . That is, agents' subjective discount rate is 5 percentage points higher than the market discount rate. This means that households have a strong incentive to front load consumption via the accumulation of external debt. The desire to front load is so strong that, for the purpose of understanding the inner workings of the model, one can safely ignore the consumption smoothing motive - the backbone of the intertemporal approach to the balance of payments. The second key ingredient is the collateral constraint. Hitting the collateral constraint is highly costly because it forces agents to deleverage, which, in turn, entails cutting present consumption in favor of future consumption, precisely what agents do not like to do. The third key ingredient of the model is the pecuniary externality created by the fact that the value of collateral depends on a price which is endogenous to the economy, but exogenous to individual households. This pecuniary externality causes the laissez-faire economy to be caught with a binding collateral constraint more often than it would were agents to internalize the pecuniary externality. The Ramsey planner, therefore, constantly negotiates a tradeoff between allowing agents to front load consumption and 
preventing them from hitting the collateral constraint too often. The economy is at the highest risk of hitting the constraint in bad times. This is because during recessions all of the components of collateral, namely, tradable output, nontradable output, and the relative price of nontradables, are depressed. As a result, it is during these circumstances that the Ramsey planner has the highest incentive to discourage borrowing. And the instrument he has to do so are capital control taxes.

The intuition given above may convey the impression that the optimality of procyclical capital control policy depends on the assumption of impatient households. But this is not the case. Making households less impatient will make the optimal capital control policy more acyclical but will not result in a countercyclical policy. The increased acyclicality is a direct consequence of the fact that, all other things equal, the more patient households are, the less frequent financial crises will be. Thus, making households more patient not only fails to overturn the predicted procyclicality of optimal capital control policy but comes at the cost of resulting in an economy that underpredicts the frequency of financial crises.

What theoretical features could be added to the present model in order to reconcile its predictions regarding the cyclicality of optimal capital controls with the conventional wisdom? One possibility is to incorporate nominal rigidities. In Schmitt-Grohé and Uribe (2016b), for example, we show that open economy models with downward nominal wage rigidity and non-optimal exchange-rate policy, such as a currency peg, can deliver the result that Ramsey-optimal capital control policy is countercyclical. In that environment, a negative demand shock, such as an increase in the country interest-rate, causes a contraction in the demand for goods. In turn the contraction in the aggregate demand for goods translates into a weaker demand for labor. Market clearing in the labor market requires a fall in the real wage. However, if nominal wages are downwardly inflexible and the nominal exchange rate is fixed, the real wage is unable to fall, giving rise to involuntary unemployment. Under these circumstances, the Ramsey planner has an incentive to lower capital controls as a way to foster debt-financed domestic absorption. During booms, market clearing in the labor market calls for an increase in the real wage. With the nominal exchange rate fixed, this requires an increase in nominal wages. But such an increase sows the seeds of larger unemployment in the contractionary phase of the cycle, given the combination of downward nominal wage rigidity and a fixed exchange rate. Individual agents understand this mechanism but are too small to internalize the fact that their own increase in demand during the boom phase exacerbates the cycle. Thus, the Ramsey planner finds it optimal to increase capital controls during the boom phase as a way to restrain demand by making agents internalize the externality. It would be of interest to characterize the cyclical properties of optimal capital control policy in the context of an economy that incorporates both a collateral constraint and 
downward nominal rigidity to ascertain whether the resulting policy prescription conforms with the conventional wisdom.

Finally, the central theme of the present paper is normative. An alternative perspective is to consider the positive aspects of the problem. Fernández, Rebucci, and Uribe (2015) examine the behavior of capital controls in a panel of 95 countries over the period 1995-2011 and find that capital controls are remarkably stable over the business cycle. At the same time, Zhou (2017) documents that capital controls are tightened during financial crisis. The model economy studied in this paper is consistent with both of these empirical regularities in one of the specifications considered, namely, when the economy is assumed to be buffeted by tradable endowment and interest rate shocks and nontradable endowment shocks are turned off. It follows that the model economy studied has predictions for optimal capital control policy that are closer to the data than to conventional wisdom. 


\section{Appendix}

In this appendix we present the first-order conditions of the Ramsey problem and derive equation (28), which links the optimal capital control tax in states in which the collateral constraint is slack to the Ramsey planner's Lagrange multiplier on the collateral constraint. In what follows we abstract from the possibility of multiple equilibria that may arise from the fact that the constraints of the Ramsey planner's problem may not describe a convex set. Specifically, we assume that the parameter values of the model are such that the constraint set is convex. ${ }^{8}$ The Lagrangian of the Ramsey problem is

$\mathcal{L}=\mathbb{E}_{0} \sum_{t=0}^{\infty} \beta^{t}\left\{U\left(A\left(c_{t}^{T}, y_{t}^{N}\right)\right)+\lambda_{t}^{R}\left[y_{t}^{T}+\frac{d_{t+1}}{1+r_{t}}-c_{t}^{T}-d_{t}\right]+\lambda_{t}^{R} \mu_{t}^{R}\left[\kappa y_{t}^{T}+\kappa \frac{1-a}{a}\left(\frac{c_{t}^{T}}{y_{t}^{N}}\right)^{\frac{1}{\xi}} y_{t}^{N}-d_{t+1}\right]\right\}$

where $\lambda_{t}^{R}$ denotes the Lagrange multiplier on the resource constraint, equation (17), and $\lambda_{t}^{R} \mu_{t}^{R}$ denotes the Lagrange multiplier on the collateral constraint, equation (25). We use the superscript $R$ on both multipliers to distinguish them from the respective Lagrange multipliers of the household's problem, $\lambda_{t}$ and $\lambda_{t} \mu_{t}$. The first-order conditions of the Ramsey problem are

$$
\begin{gathered}
U^{\prime}\left(A\left(c_{t}^{T}, y_{t}^{N}\right)\right) A_{1}\left(c_{t}^{T}, y_{t}^{N}\right)+\lambda_{t}^{R} \mu_{t}^{R} \kappa \frac{1-a}{a} \frac{1}{\xi}\left(\frac{c_{t}^{T}}{y_{t}^{N}}\right)^{1 / \xi-1}=\lambda_{t}^{R}, \\
\frac{\lambda_{t}^{R}}{1+r_{t}}=\beta \mathbb{E}_{t} \lambda_{t+1}^{R}+\lambda_{t}^{R} \mu_{t}^{R}, \\
\mu_{t}^{R}\left[\kappa y_{t}^{T}+\kappa \frac{1-a}{a}\left(\frac{c_{t}^{T}}{y_{t}^{N}}\right)^{\frac{1}{\xi}} y_{t}^{N}-d_{t+1}\right]=0, \\
\mu_{t}^{R} \geq 0,
\end{gathered}
$$

and

$$
\kappa y_{t}^{T}+\kappa \frac{1-a}{a}\left(\frac{c_{t}^{T}}{y_{t}^{N}}\right)^{\frac{1}{\xi}} y_{t}^{N}-d_{t+1} \geq 0
$$

Combining optimality condition (31) with the household's optimality condition (19) yields

$$
\lambda_{t}+\lambda_{t}^{R} \mu_{t}^{R} \kappa \frac{1-a}{a} \frac{1}{\xi}\left(\frac{c_{t}^{T}}{y_{t}^{N}}\right)^{1 / \xi-1}=\lambda_{t}^{R}
$$

which says that the marginal utility of income of the Ramsey planner, $\lambda_{t}^{R}$, is the same as the

\footnotetext{
${ }^{8}$ See, Schmitt-Grohé and Uribe (2016a) for an analysis of the case in which the constraint set fails to be convex.
} 
marginal utility of income of the private household, $\lambda_{t}$, (evaluated at the Ramsey allocation) in states in which the collateral constraint under the Ramsey policy is slack $\left(\mu_{t}^{R}=0\right)$ and exceeds $\lambda_{t}$ in states in which the collateral constraint is binding under the Ramsey policy, $\mu_{t}^{R}>0$. That is, we have shown that

$$
0<\lambda_{t} \leq \lambda_{t}^{R}
$$

Suppose that in period $t$ the collateral constraint is slack under the Ramsey plan, that is, suppose $\kappa y_{t}^{T}+\kappa \frac{1-a}{a}\left(\frac{c_{t}^{T}}{y_{t}^{N}}\right)^{\frac{1}{\xi}} y_{t}^{N}-d_{t+1}>0$. Then, by $(33), \mu_{t}^{R}=0$, and by $(31), \lambda_{t}^{R}=$ $U^{\prime}\left(A\left(c_{t}^{T}, y_{t}^{N}\right)\right) A_{1}\left(c_{t}^{T}, y_{t}^{N}\right)=\lambda_{t}$. Using (21) to replace $p_{t}$ in (18), we have that (18) also holds with a strict inequality. Therefore (22) is only satisfied if $\mu_{t}=0$. That is, $\mu_{t}^{R}=\mu_{t}=0$ in this case. We can then express $(32)$ as

$$
\lambda_{t}=\beta\left(1+r_{t}\right) \mathbb{E}_{t} \lambda_{t+1}^{R}
$$

and (20) as

$$
\left(1-\tau_{t}\right) \lambda_{t}=\beta\left(1+r_{t}\right) \mathbb{E}_{t} \lambda_{t+1}
$$

Dividing the first expression by the second yields

$$
\frac{1}{1-\tau_{t}}=\frac{\mathbb{E}_{t} \lambda_{t+1}^{R}}{\mathbb{E}_{t} \lambda_{t+1}} \geq 1
$$

The inequality follows from the fact that in any state and date, $0<\lambda_{t} \leq \lambda_{t}^{R}$. Finally, use (36) to replace $\lambda_{t+1}$ from this expression and let $\Psi_{t} \equiv \kappa \frac{1-a}{a} \frac{1}{\xi}\left(\frac{c_{t}^{T}}{y_{t}^{N}}\right)^{1 / \xi-1}$ to obtain

$$
\frac{1}{1-\tau_{t}}=\frac{\mathbb{E}_{t} \lambda_{t+1}^{R}}{\mathbb{E}_{t} \lambda_{t+1}^{R}\left(1-\mu_{t+1}^{R} \Psi_{t+1}\right)},
$$

which is equation (28). 


\section{References}

Benigno, Gianluca, Huigang Chen, Christopher Otrok, Alessandro Rebucci, and Eric R. Young, "Financial Crises and Macro-Prudential Policies," Journal of International Economics 89, 2013, 453-470.

Benigno, Gianluca, Huigang Chen, Christopher Otrok, Alessandro Rebucci, and Eric R. Young, "Optimal Capital Controls and Real Exchange Rate Policies: A Pecuniary Externality Perspective," CEPR Discussion Paper No. 9936, April 2014.

Bianchi, Javier, "Overborrowing and Systemic Externalities in the Business Cycle," American Economic Review 101, December 2011, 3400-3426.

Bianchi, Javier, Chenxin Liu, and Enrique G. Mendoza, "Fundamentals news, global liquidity and macroprudential policy," Journal of International Economics 99, 2016, S2-S15.

Bianchi, Javier, and Enrique G. Mendoza, "Optimal Time-Consistent Macroprudential Policy," Journal of Political Economy, forthcoming,

Cerra, Valerie, and Sweta Chaman Saxena, "Growth Dynamics: The Myth of Economic Recovery," American Economic Review 98, March 2008, 439-457.

Fernández, Andrés, Alessandro Rebucci, and Martín Uribe, "Are Capital Controls Countercyclical?," Journal of Monetary Economics 76, 2015, 1-14.

García-Cicco, Javier; Roberto Pancrazi; and Martín Uribe, "Real Business Cycles in Emerging Countries?," American Economic Review 100, December 2010, 2510-2531.

Jeanne, Olivier, and Anton Korinek, "Managing Credit Booms and Busts: A Pigouvian Taxation Approach," NBER working paper 16377, 2010.

Korinek, Anton, "Excessive Dollar Borrowing in Emerging Markets: Balance Sheet Effects and Macroeconomic Externalities," University of Maryland, July 2011.

Mendoza, Enrique G., "Credit, Prices, and Crashes: Business Cycles with a Sudden Stop," in Sebastian Edwards and Jeffrey A. Frankel (Eds.), Preventing Currency Crises in Emerging Markets, University of Chicago Press, Chicago, IL, 2002, 335-392.

Neumeyer, Pablo A., and Fabrizio Perri, "Business Cycles in Emerging Markets: The Role of Interest Rates," Journal of Monetary Economics 52, March 2005, 345-380.

Reinhart, Carmen M., and Vincent R. Reinhart, "After the fall," Proceedings, Economic Policy Symposium, Jackson Hole, Federal Reserve Bank of Kansas City, 17-60, 2010.

Reinhart, Carmen M., and Kenneth S. Rogoff, "Recovery from Financial Crises: Evidence from 100 Episodes," American Economic Review: Papers 65 Proceedings 104, May 2014, $50-55$.

Schmitt-Grohé, Stephanie, and Martín Uribe, "Finite-State Approximation Of VAR Processes: A Simulation Approach," Columbia University, 2009. 
Schmitt-Grohé, Stephanie and Martín Uribe, "Multiple Equilibria in Open Economy Models with Collateral Constraints: Overborrowing Revisited," NBER WP 22264, May 2016a.

Schmitt-Grohé, Stephanie and Martín Uribe, "Downward Nominal Wage Rigidity, Currency Pegs, And Involuntary Unemployment," Journal of Political Economy 124, October 2016b, 1466-1514.

Uribe, Martín, "On Overborrowing," American Economic Review Papers and Proceedings 96, May 2006, 417-421.

Uribe, Martín, "Individual Versus Aggregate Collateral Constraints and the Overborrowing Syndrome," NBER working paper 12260, May 2007.

Uribe, Martín, and Stephanie Schmitt-Grohé, Open Economy Macroeconomics, Princeton, NJ: Princeton University Press, 2017.

Uribe, Martín and Z. Vivian Yue, "Country Spreads and Emerging Countries: Who Drives Whom?," Journal of International Economics 69, June 2006, 6-36.

Zhou, Jing, "Capital Control in Banking Crisis: Inflow, Outflow and Composition," unpublished manuscript, Columbia University, March 2017. 